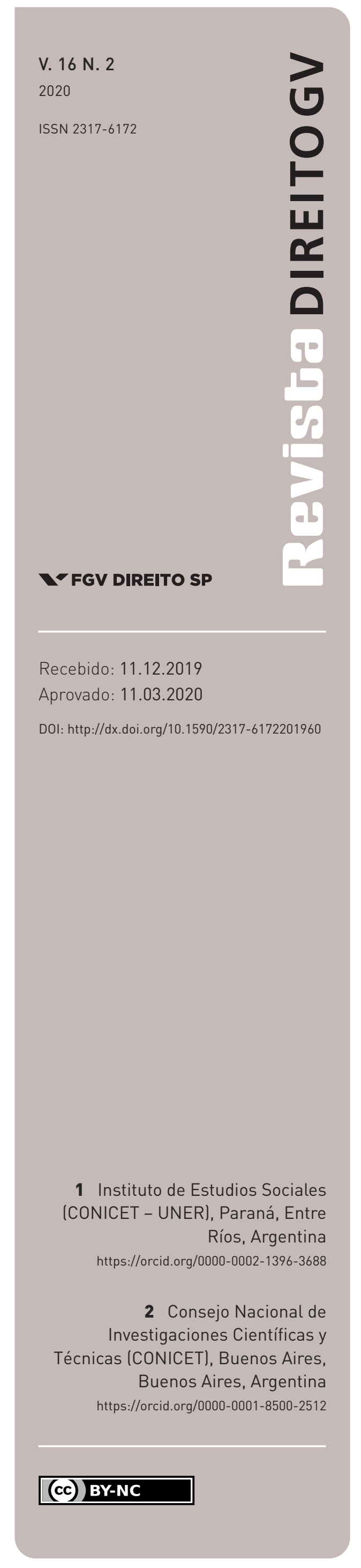

\title{
Nuevas categorías patrimoniales. La incidencia del soft law en la reciente reforma a la ley de patrimonio histórico y artístico de Argentina
}

NEW HERITAGE CATEGORIES. THE INCIDENCE OF SOFT LAW IN THE RECENT REFORM OF THE HISTORICAL AND ARTISTIC HERITAGE LAW OF ARGENTINA

NOVAS CATEGORIAS PATRIMONIAIS. A INCIDÊNCIA DA SOFT LAW NA RECENTE REFORMA DA LEI DO PATRIMÔNIO HISTÓRICO E ARTÍSTICO DA ARGENTINA

Norma Elizabeth Levrand' y María Luz Endere ${ }^{2}$

\section{Resumen}

La necesidad de modificar la ley de patrimonio histórico y artístico argentina fue un anhelo de larga data que se cristalizó en 2015. Un aspecto interesante de esta reforma es la incorporación de categorías patrimoniales y criterios que derivan de Cartas y Documentos Internacionales (originados en ICOMOS y UNESCO) que constituyen normas de soft law. Pese a que este tipo de normas no son vinculantes para los Estados, su introducción en la modificación de la ley permite analizar las características que asume la incidencia del soft law en el derecho interno argentino. En este marco, el objetivo de este trabajo consiste en analizar la introducción de un conjunto de normas de soft law en la mencionada ley y discutir su impacto desde el punto de vista conceptual, así como en la propia modalidad de gestión estatal. La incorporación de nuevas categorías patrimoniales y áreas de amortiguamiento, sumada a nuevas vías de acción administrativa (que incluyen la aplicación de mecanismos vigentes a nivel internacional y las activaciones patrimoniales), constituyen ejemplos elocuentes de un cambio paradigmático en la conceptualización del patrimonio, así como la concreción de una vía de actuación más flexible y de mayor autonomía para la autoridad de aplicación.

\section{Palabras clave}

Patrimonio cultural; legislación; soft law; categorías patrimoniales; administración estatal.

\begin{abstract}
The need to modify the Argentine historical and artistic heritage law was a longstanding desire that crystallized in 2015. An interesting aspect of this reform is the incorporation of heritage categories and criteria that derive from International Charters and Documents (originated in ICOMOS and UNESCO) which constitute soft law standards. Although these types of rules are not binding on the States, their introduction in the modification of the law allows analyzing the characteristics assumed by the incidence of soft law in Argentine domestic law. Within this framework, the objective of this paper is to analyze the introduction of a set of soft law norms in the aforementioned law and discuss its impact from the conceptual point of view, as well as in the state management modality itself. The incorporation of new heritage categories and buffer areas, added to new routes of administrative action (which include the application of mechanisms in force at international level and the patrimonial activations) constitute eloquent examples of a paradigmatic change in the conceptualization of heritage, as well as the concretion of a more flexible and more autonomous route of action for the enforcement authority.
\end{abstract}




\section{Keywords}

Cultural heritage; legislation; soft law; heritage categories; state administration.

\section{Resumo}

A necessidade de modificar a lei argentina do patrimônio histórico e artístico foi um desejo antigo que se cristalizou em 2015. Um aspecto interessante dessa reforma é a incorporação de categorias e critérios patrimoniais derivados de Cartas e Documentos Internacionais (originados no ICOMOS e UNESCO), que constituem regras de soft law. Embora esses tipos de regras não sejam vinculantes para os Estados, sua introdução na modificação da lei permite analisar as características assumidas pela incidência da soft law no direito interno argentino. Nesse contexto, o objetivo deste trabalho é analisar a introdução de um conjunto de normas de soft law na referida lei e discutir seu impacto do ponto de vista conceitual, bem como na própria modalidade de gestão estadual. A incorporação de novas categorias patrimoniais e áreas de amortecimento, somada aos novos rumos da ação administrativa lque incluem a aplicação de mecanismos vigentes em nível internacional e as ativações patrimoniais), constitui exemplos eloquentes de uma mudança paradigmática na conceituação do patrimônio, assim como a concretização de uma via de ação mais flexível e autônoma para a autoridade de execução.

\section{Palavras-chave}

Patrimônio cultural; legislação; soft law; categorias patrimoniais; administração estatal.

\section{INTRODUCCIÓN}

En la década de 1930, la influente figura del historiador, jurista e intelectual Ricardo Levene logró institucionalizar la protección del patrimonio histórico-artístico en Argentina. Luego de algunos organismos de corta vida que sirvieron de antecedentes, se creó en 1940 la Comisión Nacional de Museos y de Monumentos y Lugares Históricos (en adelante "la Comisión”). Esta entidad estuvo signada por la convicción de la necesidad de la intervención estatal en diversas actividades económicas y culturales. Asimismo, su concreción fue el resultado de diversas voces expertas que recomendaban, en el ámbito internacional, la atención de los Estados en esta temática (tales como la VII Conferencia Internacional Americana de Montevideo de 1933 y el $2^{\text {do }}$ Congreso Internacional de Historia de América de 1937). ${ }^{1}$

La Ley $N^{\circ} 12.665$ que creó la Comisión fue reglamentada por Decreto $N^{\circ}$ 84.005/1941. Conforme a estas normas, la Comisión estaba formada por un presidente y diez vocales que

1 Cabe destacar que el interés del Estado argentino por proteger el patrimonio tuvo un antecedente importante en 1913 con la sanción de la Ley N 9.080 de ruinas y yacimientos arqueológicos y paleontológicos. 
actuaban en carácter honorario. Asimismo, contaba con delegados provinciales y asesores expertos, que fueron incorporándose al organigrama durante el tiempo de vigencia de estas normas. Entre sus atribuciones esenciales caben mencionarse: a) la superintendencia exclusiva sobre los bienes históricos y artísticos, museos, monumentos y lugares históricos del dominio de la Nación y en concurrencia con las autoridades locales de aquellos bienes del dominio provincial o municipal; b) la clasificación e inventario de los monumentos, bienes y lugares de interés histórico-artístico; y c) la custodia, conservación y restauración de esos bienes. Para esta última tarea, contaba con el apoyo de la Dirección General de Arquitectura, quien debía proveer el presupuesto y los recursos técnicos para la realización de las restauraciones.

$\mathrm{Al}$ poco tiempo de iniciar sus tareas, se constataron diversos inconvenientes que limitaban el funcionamiento eficaz del organismo. La ausencia de un presupuesto propio y el carácter honorario de los vocales de la Comisión fueron los principales obstáculos observados inicialmente. Esto llevó a que, en 1948, fuera la propia Comisión que la elaborara una propuesta para la modificación de la ley que le había dado nacimiento.

Desde entonces, decenas de propuestas de modificación parcial o total de la ley han pasado por el Congreso Nacional Argentino. Si bien en 1993 se incorporaron los artículos 3 bis y 4 bis (que establecieron la consulta previa a la Comisión ante iniciativas de declarar monumentos o lugares históricos y la posibilidad de que la Comisión designe expertos para evaluar los valores de los bienes inscriptos), recién hacia fines de 2014 se logró el consenso político necesario para la modificación de la norma. La reforma producida por la Ley $\mathrm{N}^{\circ} 27.103$ mantuvo la numeración y articulado de la ley anterior, no obstante, implicó profundas modificaciones tanto en la integración como en las atribuciones y funciones de la Comisión.

En la doctrina jurídica argentina han sido escasos los trabajos dedicados al análisis de la Ley N 12.665 (Molina, 2018; Cassagne e Ibarzábal, 2016; Rodríguez, 2015). Estos trabajos abordan la novedad legislativa en su generalidad, indicando las implicancias de esta en el ordenamiento nacional.

En este marco el objetivo que guía este trabajo consiste en poner en evidencia la proyección que un conjunto de normas de soft law han tenido sobre la modificación de la Ley $\mathrm{N}^{\circ} 12.665$ y analizar su impacto desde el punto de vista conceptual, así como en la propia modalidad de gestión de la comisión. Como indica Mazuelos Bellido (2004), la expresión soft law no tiene un significado unívoco. A pesar de ello, existe acuerdo en la doctrina jurídica para incluir en esta noción aquellos instrumentos que no poseen fuerza jurígena o carácter jurídicamente vinculante y que, al mismo tiempo, detentan cierta relevancia jurídica (Ratner, 1998; Mereminskaya y Mascareno, 2005). Respecto a los agentes que pueden emitir estos documentos, en el ámbito internacional se reconocen a las organizaciones internacionales, organizaciones no gubernamentales e incluso empresas transnacionales. Asimismo, difiere la doctrina respecto del alcance de estas normas: para algunos pueden considerarse principios a los cuales la regulación nacional debe tender; para otros pueden ser caracterizadas como integrantes del sistema jurídico en tanto posean validez jurídica (Mereminskaya 
y Mascareno, 2005); finalmente otros autores sugieren que pueden conformar normas técnicas que suplan vacíos legales en temáticas aún no reguladas por los ordenamientos nacionales.

Al considerar que las normas de soft law no son vinculantes para los Estados podría deducirse que las mismas no forman parte del ordenamiento jurídico stricto sensu. No obstante, hemos argumentado que debe problematizarse el modo en que estas normas internacionales influyen en el ordenamiento interno de los Estados (Levrand, 2016 y 2018). En este sentido, la modificación de la Ley $\mathrm{N}^{\circ} 12.665$ constituye un ejemplo elocuente que permite analizar las características que asume la incidencia del soft law en el derecho interno argentino. Nuestra hipótesis es que la Ley $\mathrm{N}^{\circ} 27.103$ modifica el contenido de la Ley $\mathrm{N}^{\circ} 12.665$, incorporando en el ordenamiento vigente un conjunto de normas de soft law, haciendo posible su invocación en, al menos, dos casos: a) en las prácticas administrativas de la Comisión; y b) en la adopción de estándares internacionales para conceptualizar el patrimonio cultural. Esta incorporación no es azarosa, sino que obedece al contexto jurídico en que se modificó la norma de 1940.

Para fundamentar esta hipótesis, se parte de la constatación de que los avances más significativos y recientes en materia de patrimonio cultural, tanto desde el punto de vista conceptual como de los modos de gestionar y salvaguardar el patrimonio, han emanado de normas de soft law (i.e. Directrices Operativas de las Convenciones de la UNESCO, Recomendaciones de la UNESCO, Cartas de ICOMOS, etc.). En consecuencia, su reconocimiento en la normativa nacional es susceptible de generar un efecto derrame, de corte renovador en toda la normativa de protección del patrimonio de Argentina. Existen antecedentes de estudios que han demostrado que el soft law ya había sido receptado en la gestión de sitios patrimoniales con anterioridad a la reforma de la Ley $N^{\circ} 12.665$ de 2017 (Levrand, 2017a). En virtud de ello, el trabajo que se presenta pretende evidenciar y dimensionar el impacto de las normas de soft law en la regulación nacional del patrimonio histórico y artístico y proveer elementos para la reflexión acerca del valor de estas normas generadas en el ámbito internacional.

El trabajo se realizó a partir del análisis de documentos y de entrevistas en profundidad a actores clave de la reforma. En la estructura del texto se considera, primero, el contexto jurídico en el cual se aprobó la reforma a la Ley $\mathrm{N}^{\circ}$ 12.665. Seguidamente, se analizan aquellas normas en las cuales existen huellas de la incidencia del soft law y se procura clasificar sus incidencias. Finalmente, se presentan algunas reflexiones acerca de la reforma.

\section{EL CONTEXTO JURÍDICO DE LA REFORMA A LA LEY N ${ }^{\circ} 12.665$}

Procurar dar cuenta del contexto jurídico en el cual operaba la Ley $\mathrm{N}^{\circ} 12.665$ y aquél en el que se produce la reforma de la Ley $\mathrm{N}^{\circ} 27.103$ requiere considerar algunos hitos que han construido el derecho a la cultura y, en particular, el derecho al patrimonio cultural en Argentina.

Si bien existieron normas dedicadas a la tutela de ciertos bienes de interés histórico antes de la creación de la Comisión (Endere y Podgorny, 1997; Levrand, 2009), la formalización 
propuesta por el derecho entre 1937 y 1940 implicó la institucionalización del patrimonio histórico/artístico como un objeto de intervención y gestión por parte del Estado a partir de la puesta en marcha de un conjunto de dispositivos jurídicos y administrativos de gestión de estos bienes (Levrand, 2017b). A partir de 1940, la propia Comisión se encargaría de desarrollar una serie de mecanismos (tales como el de inventario y el de declaratoria) que institucionalizaron los bienes que conforman el patrimonio histórico-artístico en Argentina.

El siguiente hito que resulta relevante a los fines de esta contextualización es la reforma constitucional producida en 1994. En la misma se incorporó la tutela al patrimonio cultural en la norma del artículo 41, referente a la protección del ambiente. En particular, el texto indica que "las autoridades proveerán [...] a la preservación del patrimonio natural y cultural”. La redacción fue objeto de intensos debates al interior de la Convención Constituyente, que manifestaban las tensiones existentes acerca de lo patrimonial (Haidar et al., 2014, ver también Endere, 2000).

La valoración de la preservación del patrimonio cultural como un derecho fundamental en la Carta Magna afectó los alcances de otros derechos, como el derecho de propiedad. La afectación en el derecho de propiedad se vincula con dos aspectos. Por un lado, debe considerarse que con la inclusión del derecho al ambiente sano y al patrimonio cultural en la Constitución Nacional se reconocen bienes de titularidad colectiva. Por otro lado, dicho reconocimiento autoriza a restringir el derecho de propiedad privada en miras a tutelar, precisamente, los bienes de titularidad colectiva. En ambos casos se reconfigura la relación entre el sujeto jurídico, titular del derecho, y los bienes sobre los que este recae. En breve consideraremos esta afectación y la nueva configuración del derecho de propiedad a partir de la reforma al Código Civil y Comercial.

Por otra parte, la reforma constitucional modificó las competencias de la Nación y de las provincias en esta temática. El propio artículo 41 establece la facultad de la Nación de dictar leyes de presupuestos mínimos, que pueden ser complementadas por las provincias. De este modo, se incluyó una nueva forma de reparto de competencias, complementaria, en la cual la Nación sanciona las bases (por ejemplo, respecto de la educación o el ambiente) y las provincias complementan, maximizando esta regulación. Por esta función, esta división de competencias se ha denominado competencia provincial maximizadora (Esaín, 2008).

Desde la reforma de la Constitución y sobre todo durante la década de 1990 se multiplicaron las presentaciones ante el Congreso de proyectos de leyes de patrimonio de distinto alcance; sin embargo, ninguno de ellos logró ser sancionado, quedando aún pendiente la tarea de sancionar una ley de presupuestos mínimos del patrimonio cultural (Endere, 2000; Endere y Rolandi, 2007). ${ }^{2}$

2 En 1999 se sancionó la Ley $\mathrm{N}^{\circ}$ 25.197, que crea un registro único de bienes culturales de la Nación. Esta norma define "bienes culturales" como "todos aquellos objetos, seres o sitios que constituyen la expresión 
De modo concordante, la reforma constitucional indicó que los tratados tienen jerarquía superior a las leyes e incluso estableció que un conjunto de tratados de Derechos Humanos posee jerarquía constitucional. Entre los primeros, Argentina ha ratificado un conjunto de tratados dedicados al patrimonio cultural. ${ }^{3}$ Entre las normas de Derechos Humanos que poseen jerarquía constitucional, merecen destacarse, en primer lugar, el Pacto Internacional de Derechos Económicos, Sociales y Culturales que incluye el derecho a participar de la vida cultural, enunciación que fundamenta el derecho a la cultura en el ámbito internacional. En segundo lugar, la Convención Americana de Derechos Humanos que prevé la función social de la propiedad en su artículo 21.

Estas normas de derecho internacional son complementadas y reguladas a partir de normas de soft law en muchos casos. Por ejemplo, las Directrices Prácticas para la Aplicación de la Convención del Patrimonio Mundial, Cultural y Natural configuran el derecho al cual se sujeta el Comité del Patrimonio Mundial, como también los Estados parte que desean postular un sitio para su inclusión en las listas y también las ONGs que son organismos consultivos del Comité.

o el testimonio de la creación humana y la evolución de la naturaleza y que tienen un valor arqueológico, histórico, artístico, científico o técnico excepcional. El universo de estos bienes constituirá el patrimonio cultural argentino". A su vez establece que son "bienes culturales histórico-artísticos todas las obras del hombre u obras conjuntas del hombre y la naturaleza, de carácter irreemplazable, cuya peculiaridad, unidad, rareza y/o antigüedad les confiere un valor universal o nacional excepcional desde el punto de vista histórico, etnológico o antropológico, así como las obras arquitectónicas, de la escultura o de pintura y las de carácter arqueológico" (art. 2). Entre las categorías de "bien cultural histórico-artístico" comprende bienes muebles e inmuebles, entre ellos: los bienes inmuebles del patrimonio arquitectónico de la Nación (art. 2.6).

La autoridad de aplicación es la Secretaría de Cultura de la Nación, que está facultada para ejercer la superintendencia sobre el conjunto de los bienes que constituyen el patrimonio histórico-cultural de la Nación y coordinar con los gobiernos provinciales y con el Gobierno de la Ciudad de Buenos Aires la implementación de una red de registros comunes. Esta norma no ha sido hasta la fecha reglamentada. Respecto de la emergencia de ciertos dispositivos que pueden considerarse normas de presupuestos mínimos, puede consultarse Levrand, 2015.

3 Entre ellos: la Convención para la Protección de los Bienes Culturales en caso de Conflicto Armado (UNESCO, La Haya, 1954); la Convención sobre las Medidas que deben Adoptarse para Prohibir e Impedir la Importación, la Exportación y Transferencia de Propiedad Ilícitas de Bienes Culturales (UNESCO, París 1970), la Convención sobre la Protección del Patrimonio Mundial, Cultural y Natural (UNESCO, París, 1972); la Convención sobre Objetos Culturales Robados o Exportados Ilegalmente (UNIDROIT, 1995); la Convención sobre Defensa del Patrimonio Arqueológico, Histórico y Artístico de las Naciones Americanas (OEA, San Salvador, 1976); la Convención para la Salvaguardia del Patrimonio Cultural Inmaterial (UNESCO, París, 2003), la Convención sobre la Protección y Promoción de la Diversidad de las Expresiones Culturales (UNESCO, 2005) y la Convención sobre la Protección del Patrimonio Cultural Subacuático (UNESCO, 2001). 
Otras veces, los organismos internacionales de los cuales emanan los tratados (como UNESCO y OEA) establecen recomendaciones que no tienen carácter vinculante para los Estados parte. ${ }^{4}$

En síntesis, ya sea como consecuencia de la ratificación de un tratado internacional o por integrar un organismo internacional, el Estado nacional recibe un conjunto de normas de soft law que reglamentan, establecen principios o declaran intenciones acerca de la tutela jurídica del patrimonio cultural.

Finalmente, el tercer hito que consideramos relevante mencionar para dar cuenta del contexto de producción de la Ley $\mathrm{N}^{\circ} 27.103$ es la reforma que se produjo, en 2014, al Código Civil y Comercial argentino. En esta reforma cobró particular relevancia la inclusión de normas que tutelan derechos de incidencia colectiva. Así, en el artículo 14 se establece: "La ley no ampara el ejercicio abusivo de los derechos individuales cuando pueda afectar al ambiente y a los derechos de incidencia colectiva en general”. De modo concordante, el artículo 240 establece que el ejercicio de los derechos individuales no debe afectar "el funcionamiento ni la sustentabilidad de los ecosistemas de la flora, la fauna, la biodiversidad, el agua, los valores culturales, el paisaje, entre otros".

La reforma del Código Civil y Comercial fue la oportunidad de transformar las normas relativas a la propiedad privada que databan, en Argentina, de la concepción decimonónica. Ya desde mediados del siglo XX la doctrina jurídica comenzó a desarrollar la "teoría pluralista de la propiedad" (Rodotá, 1986:49). La misma se fundamenta en la observación de una ruptura del concepto unitario del derecho de propiedad, tal como fue acuñado por los teóricos decimonónicos. Así, se ha indicado una transformación en la concepción de la propiedad privada, como instituto centrado en la construcción de un sujeto titular abstracto, unitario, que posee ciertos poderes sobre las cosas, hacia una noción cuyo eje es el elemento objetivo encarnado en el "fin" de la misma (Cordero Quinzacara, 2008). En Argentina surgieron también tendencias doctrinarias, afines a la protección de derechos sociales, que promovían nuevas concepciones del derecho de propiedad (Francchini, 2005). Algunos autores han indicado que estas concepciones se orientan a garantizar la integridad física y la afectación al fin público de este tipo de propiedad (Moreu Carbonell, 2003), e incluso que es necesario dar cuenta de una construcción alternativa del modelo propietario que permita colocar la propiedad privada en idéntico nivel con otros derechos fundamentales (Sozzo, 2009).

4 Así, podemos mencionar la Recomendación relativa a la protección de la belleza y del carácter de los lugares y paisajes (OEA, Washington, 1962), la Recomendación sobre la Salvaguardia de la Cultura Tradicional y Popular (UNESCO, París, 1989) o la Recomendación sobre el paisaje urbano histórico (UNESCO, París, 2011) entre otras. 
La tensión entre el disfrute individual del derecho de dominio y la fruición colectiva establecida en el derecho de acceso y goce del patrimonio cultural fue objeto de indagaciones en el ámbito jurídico que dieron origen a las normas indicadas (Colombato, 2016; Sozzo, 2019)

Un breve examen de las fuentes que ilustraron la introducción de los artículos mencionados permite dar cuenta que el jurista Ricardo Lorenzetti, presidente de la Comisión Redactora del Proyecto de Código Civil y Comercial (y, a la sazón, presidente de la Corte Suprema de Justicia de la Nación), había desarrollado una teoría del derecho ambiental en la cual se considera al ambiente como un "macro-bien". Considerado de esta manera, el ambiente funciona como un "sistema", que excede la suma de sus elementos, sino que implica la interrelación de estos. En su texto, Lorenzetti menciona como elementos: la fauna, la flora, el agua, el paisaje, los aspectos culturales, el suelo, entre otros (2008:15). Asimismo, en otro texto (Lorenzetti, 2005), este autor analizó el concepto de "paisaje" y sus incidencias en el ordenamiento argentino a partir del estudio del derecho comparado. Damos cuenta de estos antecedentes a fin de ilustrar que la inclusión del artículo 240 en el Código Civil y Comercial no surge accidentalmente y que las nociones de "valores culturales" y "paisaje" se encontraban desarrolladas por la doctrina. ${ }^{\mathbf{5}}$

El reconocimiento de los valores culturales en la misma jerarquía que los ambientales, unido a la mención expresa del paisaje, exigen revisar la interpretación y aplicación de las normas jurídicas que tutelan el patrimonio cultural. Ello teniendo en cuenta que en múltiples normas el propio Código Civil y Comercial establece la preeminencia del ejercicio de los derechos de incidencia colectiva por sobre los derechos individuales (Vera, 2016, ver también Endere y Colombato 2017).

Si bien hasta el momento hemos reseñado el contexto regulatorio nacional, la Comisión también consideró la necesidad de actualizar los criterios con los cuales se realiza el Registro Nacional de Bienes Históricos e Histórico-Artísticos. Así, en 1991 se dictó la Disposición Interna $\mathrm{N}^{\circ}$ 6/91 que clasificó los bienes que integran el mencionado Registro, a partir de cuatro grupos tipológicos, que se exponen en el Cuadro 1.

5 No es objeto de este trabajo realizar un análisis pormenorizado de ambas nociones, pero es necesario aclarar que la jurisprudencia también desarrolló concepciones acerca de la protección del paisaje y de algunos bienes culturales en Argentina. 


\section{Cuadro 1: Grupos tipológicos eSTABleCidos eN LA DisPOSICIÓN INTERNA Nº 6/9I} MONUMENTO HISTÓRICO NACIONAL MONUMENTO HISTÓRICO-ARTÍSTICO NACIONAL MONUMENTO HISTÓRICO Y ARTÍSTICO NACIONAL

\begin{tabular}{|c|c|}
\hline \multirow[b]{4}{*}{ LUGAR HISTÓRICO NACIONAL } & SITIO HISTÓRICO \\
\hline & SOLAR HISTÓRICO \\
\hline & SITIO ARQUEOLÓGICO \\
\hline & PUEBLO HISTÓRICO \\
\hline \multirow[b]{5}{*}{ BIEN DE INTERÉS HISTÓRICO } & SEPULCRO HISTÓRICO \\
\hline & ÁRBOL HISTÓRICO \\
\hline & PUEBLO, BARRIO O CENTRO HISTÓRICO \\
\hline & PAISAJE URBANO Y NATURAL ICONJUNTOS Y SECUENCIAS \\
\hline & $\begin{array}{l}\text { EDIFICIO Y ACTIVIDAD ISOCIAL, INSTITUCIONAL, ARTÍSTICA, } \\
\text { INDUSTRIAL, CIENTÍFICA, OBRAS DE INGENIERÍA, ETC.) }\end{array}$ \\
\hline & $\begin{array}{l}\text { BIENES INMUEBLES (EDIFICIOS, CONSTRUCCIONES, GRUPOS } \\
\text { ESCULTÓRICOS, MURALES, PARQUES, JARDINES) }\end{array}$ \\
\hline BIEN DE INTERÉS HISTÓRICO-ARTÍSTICO & BIENES MUEBLES (OBJETOS HISTÓRICO-ARTÍSTICOS) \\
\hline
\end{tabular}

Fuente: elaboración propia.

En el Cuadro 1 pueden resaltarse algunas tipologías como pueblo histórico o paisaje urbano y natural que dan cuenta del interés con el cual los integrantes de la Comisión consideraban las transformaciones producidas en el ámbito internacional respecto de los criterios de valoración. En la Disposición Interna $\mathrm{N}^{\circ}$ 5/91, destinada a definir cada uno de los grupos tipológicos, se expresa que los criterios incorporados por la Comisión para definir y actualizar el concepto de patrimonio se corresponden "con la opinión de los expertos y las recomendaciones formuladas por los congresos de especialistas de este tema en el orden nacional 
e internacional". Ello da cuenta de que la propia Comisión consideró los documentos generados por los expertos para realizar la catalogación de los bienes declarados incluso antes de las reformas jurídicas en el ámbito nacional.

A partir de estas observaciones, parece incluso tardía la aparición de un proyecto de reforma de la Ley $\mathrm{N}^{\circ} 12.665$ en el cual se incluyesen las categorías de “poblado histórico" y "área urbana histórica” en 2003. "Un estudio exploratorio de los proyectos de reformas a la Ley $\mathrm{N}^{\circ} 12.665$ presentados en las últimas décadas permite indicar que en su mayoría refieren a la modificación de las sanciones por incumplimiento de la ley y a la posibilidad de acordar con las provincias y municipios la exención impositiva sobre los inmuebles registrados por la Comisión.

Desde el inicio del nuevo milenio solo se presentaron tres proyectos de reforma integral de la ley, bastante similares entre sí y provenientes del partido político gobernante. En ellos se establecen claramente las atribuciones de la Comisión, incorporándose, entre otras facultades, la de establecer “áreas de amortiguación visual” y “áreas de amortiguación” en el entorno de los monumentos. La Comisión debía coordinar con la autoridad local las restricciones urbanísticas que correspondan, lo cual implica una actuación conjunta entre los niveles nacional y municipal a fin de garantizar el derecho al patrimonio cultural. Así lo entiende Reyna (2014), para quien la incorporación de un conjunto de derechos de incidencia colectiva en la reforma constitucional de 1994 produjo alteraciones al sistema de competencias, ya que estos derechos operan de modo transversal y exigen actuaciones conjuntas de más de un nivel estatal. Estas actuaciones no implican una articulación de niveles, sino la selección de los componentes claves de cada sistema jurídico (nacional y provinciales) y su sincronización a fin de garantizar un derecho fundamental.

Otra coincidencia relevante en los proyectos presentados es la tipificación taxativa de las categorías de bienes que gestiona la Comisión. ${ }^{7}$ En la misma se incluyen y amplían las categorías definidas en la Disposición $\mathrm{N}^{\circ}$ 6/91. Sin perjuicio del análisis que se realizará en el apartado siguiente, una integrante de la Comisión consideró que la sola mención de las categorías implicaba una debilidad de la norma jurídica: “... habría que definirlas [...] y desde el punto de vista jurídico determinar si existe alguna diferencia entre una y otra en cuanto al régimen, y no la hay, sigue siendo un régimen único para todo tipo de bienes...” (Com. Pers. 12/10/2018).

$6 \quad$ Nos referimos al Proyecto s-2440-2003.

7 En un proyecto de 2006 se mencionan 11 categorías: 1. Monumento histórico nacional, 2. Lugar histórico nacional, 3. Poblado histórico nacional, 4. Área urbana histórica nacional, 5. Área de amortiguación visual, 6. Bien de interés histórico nacional, 7. Bien de interés artístico nacional, 8. Bien de interés arquitectónico nacional, 9. Sepulcro histórico nacional, 10. Paisaje cultural nacional, 11. Itinerario cultural nacional. A estas categorías se agregó, en un proyecto de 2010, las categorías bien de interés industrial nacional y bien de interés arqueológico nacional, que se mantuvieron en el proyecto que se convirtió en ley en 2015. 
Los tres proyectos prevén una cláusula por la cual la Comisión y los gobiernos locales pueden realizar gestiones para que los titulares privados de bienes declarados en el marco de la ley obtengan préstamos a tasas subsidiadas para su conservación. Si bien la Ley $\mathrm{N}^{\circ} 12.665$ estableció la posibilidad de acordar con los particulares el modelo de asegurarla, ello ocurrió pocas veces (Levrand, 2017a).

Las connotaciones de la cláusula analizada son, sobre todo, simbólicas. Ellas remiten al fomento que el Estado puede realizar, a través de la Comisión y los gobiernos locales, para que los particulares puedan mantener en buen estado de conservación los bienes declarados de interés histórico, artístico, industrial, arquitectónico, etc.; aunque ratifica que es obligación de los titulares dominiales conservar estos bienes. Las discrepancias acerca del sujeto obligado a preservar los bienes del patrimonio cultural (sobre todo arquitectónico) poseen antecedentes valiosos en la jurisprudencia. Así, en 1923 la Corte Suprema de Justicia de la Nación indicó respecto de la "Casa del Acuerdo de San Nicolás" que "en manos de las propietarias ha estado el poder y la facultad de haber desnaturalizado el edificio, ya destruyéndolo o modificándolo" (Fallos, 143:432). Noventa años después, la Corte Suprema indicaría, frente al deterioro de la Casa Mansilla, que "el mayor peso del reproche debe necesariamente recaer sobre el Estado Nacional” (Fallos, 336:1390).

La cláusula que finalmente resultó aprobada establece que "La Comisión Nacional podrá gestionar o apoyar las gestiones de terceros ante organismos públicos o privados, para la obtención de créditos de fomento para la conservación de los bienes declarados, en cualquiera de sus clases”. De manera más laxa y abierta, considera la posibilidad de que la Comisión acompañe las gestiones de los particulares.

Finalmente, debe destacarse que en los proyectos de reforma presentados en 2010 y 2012 se establece un presupuesto propio para la Comisión. Hasta la sanción de la Ley $\mathrm{N}^{\circ} 27.103$ la Comisión realizaba las intervenciones dedicadas a conservar los bienes arquitectónicos a través del presupuesto de obras públicas, administrado por dicha cartera. El reclamo por un presupuesto propio, que permitiera actuar conforme las prioridades establecidas por la Comisión, surgió desde sus primeras intervenciones y se ha mantenido a través del tiempo (Levrand, 2017b). La modificación permitió que la Comisión tenga un presupuesto que depende de la actual Secretaría de Cultura de la Nación y que se desagrega en proyectos de restauración y puesta en valor de monumentos, museos y preservación institucional de bienes declarados.

En este contexto jurídico la reforma integral a la Ley $\mathrm{N}^{\circ} 12.665$ implicó no solo modificaciones al modo de trabajo y organización de la Comisión, sino también cambios en las prácticas y los conceptos que la misma utiliza en su accionar. Sin embargo, una integrante de la Comisión reconoce que: “...en la práctica, esa reforma no se ve demasiado, no se ven cambios sustanciales...” (Com. pers. 12/10/2018).

En el próximo apartado se abordará la influencia del soft law en las prácticas y conceptos de la Comisión. 


\section{LA INCIDENCIA DEL SOFT LAW}

El impacto que los estándares internacionales de regulación del patrimonio cultural producen sobre el derecho administrativo nacional no es objeto principal de atención de los juristas. Sin embargo, las modificaciones producidas a la Ley $\mathrm{N}^{\circ} 12.665$ en 2015 dan cuenta de una apertura de la autoridad regulatoria estatal a dichos estándares y a la posibilidad de suplantar la regulación administrativa nacional por principios y normas establecidos en documentos no vinculantes.

Como indican Galbraith y Zaring (2014:748), el incremento de la globalización y la consecuente modificación de tradiciones nacionales de regulación incrementaron la aplicación de normas de soft law por parte de las administraciones estatales. Estos autores indican que, como una matriz habitual, la implementación de los estándares internacionales formalizados a través del soft law recae en las agencias administrativas.

Como indica Cerda Dueñas (2017), atento a la variedad de categorías de instrumentos, costumbres, actos unilaterales y principios que pueden considerarse soft law, es necesario precisar, en cada caso, la condición de los que se encuentran bajo análisis. En este sentido, por ejemplo, la evaluación de la postulación de un sitio a la Lista del Patrimonio Mundial, realizada por ICOMOS, no es un documento vinculante para el Comité del Patrimonio Mundial y tampoco para los Estados parte. Sin embargo, en el caso de las Misiones Jesuíticas Guaraníes en Argentina, esta evaluación fue considerada parte de un compromiso político por el cual el Estado nacional fomentó un conjunto de acciones y propició ciertas decisiones políticas por parte de los Estados provinciales. Estas acciones y decisiones se exteriorizan de diversas maneras y traslucen políticas públicas cuyo grado de solidez es variable. Algunas actuaciones políticas identificadas incluyen, en primer lugar, las acciones encaminadas a elaborar el documento de postulación de los sitios. También, aunque con menor grado de formalización, se explicitan en acciones sobre el territorio.

Por otra parte, en relación a las Directrices Operativas de la Convención del Patrimonio Mundial, Cultural y Natural:

Ante la instalación de un complejo industrial cercano a las Ruinas de Santa Ana, la operatividad de las Directrices se visibilizó particularmente en acciones de la Comisión Nacional de Monumentos, Lugares y Bienes Históricos. Este organismo nacional operó hacia el nivel internacional, realizando gestiones ante UNESCO a fin de mostrar que la instalación industrial no afectaba la protección del bien en cuestión. Asimismo, operó hacia el nivel subnacional, implementando presiones para regular la zona de amortiguación del bien. (Levrand, 2018)

En otro caso, la Comisión Nacional de Monumentos, junto a la Comisión Nacional Argentina de Cooperación con la UNESCO (CONAPLU), actuaron como organismo de revisión de un proyecto de ordenanza de la Municipalidad de Colonia Caroya (en la cual se encuentra 
emplazado un bien inscripto en la Lista del Patrimonio Mundial) a fin de controlar la adecuación de la reglamentación a las normas internacionales (incluyendo, entre las mismas, las Directrices Operativas de la Convención). Como se indicó, la implementación de normas de soft law, habitualmente realizada por la administración pública (en este caso, la CONAPLU), permite advertir la influencia del ordenamiento internacional sobre el ordenamiento interno (Levrand, 2017a).

En todos los casos mencionados las normas de soft law fueron introducidas antes de la reforma de 2017. En cambio, a partir de la sanción de la Ley $\mathrm{N}^{\circ} 27.103$, es el propio Congreso que habilita esta implementación a través de una serie de cláusulas. Las mismas pueden ser clasificadas, analíticamente, en: a) la aplicación de soft law en relación a las prácticas de la Comisión y b) cláusulas que receptan estándares internacionales de soft law en la conceptualización del patrimonio cultural.

\section{a) Cláusulas Que Habilitan la APLICACIÓN DEL SOFT LAW EN RELACIÓN CON LAS PRÁCTICAS} DE LA COMISIÓN

Como indicamos, la reforma incluye un conjunto de cláusulas que habilitan a que la administración nacional (en este caso la Comisión) pueda aplicar normas de soft law en la regulación de sus prácticas. Entre las más relevantes pueden encontrarse: los artículos 1 ter a) y 1 ter c) del Decreto Reglamentario $\mathrm{N}^{\circ} 2.525 / 15$ que posicionan a la Comisión como una agencia productora de recomendaciones acerca del patrimonio cultural; y el artículo 1 ter d) que considera de modo destacado la labor de los expertos en la evaluación de los méritos de un bien para ser considerado parte del patrimonio cultural argentino.

Los primeros artículos reseñados establecen que, como una consecuencia de poseer la superintendencia sobre los bienes declarados protegidos en los términos de la ley, la Comisión "emitirá recomendaciones sobre la forma más adecuada de preservar el bien, pudiendo solicitar al MINISTERIO DE CULTURA la paralización de las obras que no se ajusten a las pautas establecidas". Si bien la Comisión emitió recomendaciones acerca del mejor modo de conservar los bienes declarados, esta tarea no tenía un destinatario específico. Así, pueden encontrarse recomendaciones dirigidas tanto a los gestores de los monumentos históricos como a las autoridades de distintos niveles de gobierno. A partir del análisis de algunos casos concretos, se advierte que el modo más corriente de intervención comienza con la notificación que los responsables de los bienes inscriptos cursan a la Comisión con la descripción de los proyectos que implican una intervención sobre los bienes declarados. El equipo técnico de la Comisión realiza un dictamen acerca de la intervención, el cual puede ser aprobado por el plenario de los miembros del Directorio. De este modo, la Comisión actúa como fiscalizadora de las acciones que se realizan sobre los bienes declarados. No obstante, esta fiscalización se limita a aquellas acciones que han sido comunicadas a la Comisión, ya que el organigrama de la misma no permite que los delegados provinciales (quienes no cuentan con salario ni dinero para movilidad) realicen inspecciones regulares en cada uno de los bienes declarados. 
La modificación en la norma jurídica indica que la Comisión podrá solicitar al Ministerio de Cultura la paralización de obras, lo que da cuenta de la imprecisión de la reglamentación y las dificultades en la gestión de los bienes, también indicada por una entrevistada, quien refiriéndose a la necesidad de solicitar al Ministerio de Cultura la autorización para paralizar obras, senãló: "la reglamentación no nos ayudó para nada en la gestión" (Com. Pers. 12 /10/2018). Esta suspensión solo será efectiva en el caso que la obra dependa de esta jurisdicción, puesto que, como el artículo reglamentado establece, los bienes declarados pueden pertenecer al Estado Nacional, Provincial, Municipal o a particulares.

En otro orden, es de destacar que a diferencia de las comisiones patrimoniales que se han organizado en diversas jurisdicciones municipales argentinas, la Comisión Nacional posee escasas herramientas para informarse de las intervenciones que se hayan realizado sobre inmuebles que habían sido declarados monumentos o lugares históricos. ${ }^{\mathbf{8}}$ En el caso de los inmuebles declarados en los términos de la Ley $\mathrm{N}^{\circ} 12.665$, la modificación puede canalizarse en la administración municipal sin contar con una aprobación de la Comisión Nacional.

Un ejemplo elocuente es el caso de la Ciudad Prehispánica de Tolombón que fue declarada Monumento Histórico mediante el Decreto $\mathrm{N}^{\circ} 21.483$ del 12 de agosto de 1944. La declaración de las ruinas como monumento nacional tiene solo valor de proclamación. Nunca fue delimitado el sitio, ni levantado un plano topográfico, tampoco ha sido cercado el terreno ni designado un guardián. En un informe realizado hace algunos años se indicó:

El sitio presenta serios problemas de conservación debido, por una parte, a las excavaciones clandestinas efectuadas con el objeto de obtener piezas arqueológicas para su comercialización y, por otra, por el impacto generado por acciones antrópicas y por la degradación natural. Además, debe tenerse en cuenta que la extensión del sitio era mucho mayor que la superficie que ocupa actualmente, ya que las áreas perimetrales de este fueron recortándose debido a la construcción de la ruta nacional, de viviendas y, en los últimos años, por la instalación de un hotel y de viñedos en sus alrededores. (Endere et al., 2013:212)

Por otra parte, la reglamentación del artículo 1 ter c) establece que la Comisión puede dictar recomendaciones acordes con las pautas establecidas en las Convenciones y Cartas internacionales acerca de los criterios y pautas de selección, clasificación y valoración de los bienes históricos o culturales. En este punto se incorpora, al mismo nivel de las normas obligatorias para el Estado Nacional, un conjunto de recomendaciones y cartas emitidas por diversos organismos, que no tienen fuerza jurígena (normas de soft law).

8 En el caso de las comisiones municipales, su intervención se realiza como una etapa previa a la aprobación de la obra, de modo que el procedimiento administrativo garantiza el conocimiento de esta. 
Finalmente, el artículo 1 ter d) de la Ley $\mathrm{N}^{\circ} 12.665$ establece que, a solicitud del Congreso de la Nación, la Comisión podrá designar expertos para realizar la valoración de los bienes. Estos dictámenes, que serán presentados por escrito, no son vinculantes y deben ser refrendados por la Comisión para poseer validez. Conforme la redacción y concordancia con el artículo 4, este dictamen experto del valor patrimonial de los bienes puede transformarse en un paso previo a la declaración de estos como monumento o lugar histórico nacional.

Si bien la incidencia de los discursos expertos en las normas jurídicas puede manifestarse al momento de su creación o modificación; en el caso que estamos analizando, la consideración de los criterios de valoración expertos previamente a la declaración de un bien habilita la introducción de concepciones elaboradas en el ámbito académico internacional y plasmadas en normas de soft law. Como se indicó, estas normas provienen tanto de organismos internacionales como de organizaciones no gubernamentales internacionales. En el ámbito que nos ocupa, un conjunto de actores globales, como el Consejo Internacional de Monumentos y Sitios (ICOMOS), la UNESCO, el Fondo del Patrimonio Mundial (conocido por sus siglas en inglés como WMF), el Banco Interamericano de Desarrollo (en adelante BID), entre otros, establecen regulaciones de soft law que son acogidas primero por los expertos. Dado que, en muchos casos, estos componen los cuadros técnicos al interior de la administración, estos criterios se manifiestan en la manera en que el Estado produce un conocimiento científico sobre los sitios y es capaz de desplegar este conocimiento con fines públicos (en particular en políticas públicas).

Cabría preguntarse, entonces, si esta norma otorga un margen de actuación amplio a la Comisión Nacional, en el sentido que podría plantear a nivel administrativo cuestiones que deberían ser abordadas en el Poder Legislativo. En ese aspecto, sería útil observar la trayectoria de gestión de la propia Comisión, que nunca se caracterizó por un comportamiento que podría considerarse audaz o temerario, sino por el contrario, quizás excesivamente reglamentarista.

Sin embargo, la norma modificada le da cierto margen de actuación que en la práctica resulta útil, sobre todo a la hora de presentar las postulaciones a la Lista del Patrimonio Mundial o a la Lista Representativa del Patrimonio Cultural Intangible. En estos casos se actúa en el marco de las convenciones ratificadas por Argentina, aunque apelando a las normas de soft law.

Así, a principios de la década de 2010, previos a presentar la nominación de los tramos de Argentina para el Qhapac Ñan (Camino Principal Andino, inscripto en 2016), surgió la necesidad de impulsar la declaratoria de monumentos o lugares históricos nacionales de aquellos tramos considerados más significativos y que no contaban con normas de protección específicas. La modalidad de registro de los bienes consistía en una planilla que exigía consignar los datos catastrales. Cuando se trataba de tramos de caminos que involucraban grandes áreas, con diversidad de paisajes e incluso montañas como el volcán Llullaillaco, la dificultad de catalogarlos con los mismos criterios que un inmueble (es decir a través de datos catastrales, etc.) fue evidente. En ese momento los expertos resolvieron esta situación 
individualizando esos espacios a través de puntos georeferenciados, a pesar de que esta identificación no era considerada suficiente por la Ley $\mathrm{N}^{\circ} 12.665$ previa a la reforma. Todas estas cuestiones prácticas impidieron contar con una norma especial de protección a nivel nacional que reforzara la presentación de la nominación. Ésta se sumó a la necesidad de una reforma para volverla más acorde a las categorías empleadas a nivel internacional, así como a cuestiones más prácticas vinculadas con la catalogación.

\section{b) CLÁUSUlas QUE RECEPTAN ESTÁNDARES INTERNACIONALES DE SOFT LAW EN LA CONCEPTUALIZACIÓN DEL PATRIMONIO CULTURAL}

Como se indicó, la característica de las normas de soft law es que su contenido normativo no goza de valor obligatorio, aunque contienen normas de conducta que promueven la práctica estatal en cierta dirección. En general, se tratan de manifestaciones jurídicas de principios y objetivos, y no de reglas detalladas y precisas. Una de las particularidades de la reforma a la Ley $\mathrm{N}^{\circ} 12.665$ es la introducción de estos estándares que modifican el concepto de patrimonio cultural sostenido hasta el momento a través de nuevas categorías de protección, la introducción de la dimensión cultural del desarrollo sustentable o la consideración del área de amortiguación.

En los casos reseñados se advierte que un cúmulo de nociones desarrolladas en el ámbito internacional son receptadas por la regulación, modificando las posibilidades de actuación de la Comisión. Existen tres ejemplos en la norma reformada que serán analizados a continuación:

\section{b) i . Nuevas categorías Patrimoniales}

Un cambio paradigmático se produjo en la normativa nacional a partir de la introducción de nuevas categorías de protección como los paisajes e itinerarios culturales (art. 4.12 y 4.13 de la Ley $\left.\mathrm{N}^{\circ} 12.665\right)$. Estas categorías que estaban presentes en la normativa internacional no habían sido receptadas como tales en las normas nacionales relativas al patrimonio cultural.

Al respecto cabe señalar que en 2008 ICOMOS aprobó la Carta de Itinerarios Culturales dada la necesidad de adoptar un concepto que diera cuenta de "la importancia creciente de los valores del entorno y de la escala territorial, y poner de manifiesto la macroestructura del patrimonio a diferentes niveles". En la introducción del mencionado documento se señala la necesidad de contar con una "noción más extensa del patrimonio" que permita "explicar y salvaguardar las relaciones significativas directamente asociadas con su medio cultural e histórico, así como con su entorno natural o hecho por el hombre".

En dicho documento se explicita que, si bien se trata de una nueva categoría, esta guarda armonía y no se solapa con otras categorías o tipos de bienes tales como monumentos, ciudades, paisajes culturales, patrimonio industrial, etc., que pueden existir en su seno. ${ }^{9}$

9 Se define al itinerario cultural "como toda vía de comunicación terrestre, acuática o de otro tipo, físicamente determinada y caracterizada por poseer su propia y específica dinámica y funcionalidad histórica al 
La consideración del contexto tanto natural como cultural, los componentes tangibles e intangibles de esta categoría patrimonial y su carácter dinámico son otros de sus elementos característicos. En este sentido la categoría itinerario cultural "tiene un carácter innovador, complejo y multidimensional que introduce y representa un aporte de valor cualitativo a la teoría y a la práctica de la conservación del patrimonio" (Introducción). ${ }^{10}$

Esta carta, así como las conclusiones de otras reuniones de expertos (e.g. "Rutas como parte de nuestro patrimonio cultural" - Madrid, 1994) han sido discutidas por el Comité del Patrimonio Mundial (ver WHC95/CONF.203/16). Como resultado de ello se incluyó un anexo en las Directrices Operativas de 2017 donde se establecen recomendaciones aplicables a itinerarios y paisajes culturales que deseen ser inscriptos como patrimonio mundial. Entre otros aspectos se establece que deben considerarse el marco natural, así como la dimensión tangible e intangible del itinerario y respetar los deseos de los pueblos afectados (UNESCO, 2017:86).

Por otra parte, cabe destacar que el concepto de paisaje cultural comenzó a ser introducido en los documentos relativos al patrimonio desde los años 1960. En efecto, en la Recomendación relativa a la protección de la belleza y el carácter de los lugares de la UNESCO (1962) se hace referencia a "los paisajes naturales, rurales o urbanos debidos a la naturaleza o a la mano del hombre que ofrecen un interés cultural o estético". Sin embargo, no fue sino hasta 1992 cuando el Comité del Patrimonio Mundial adoptó la categoría de paisaje cultural. Este ha sido definido como bien cultural y representa las “obras conjuntas del hombre y la naturaleza” citadas en el artículo 1 de la Convención. Los paisajes culturales "ilustran la evolución de la sociedad humana y sus asentamientos a lo largo del tiempo, condicionados por las limitaciones y/o oportunidades físicas que presenta su entorno natural y por las sucesivas fuerzas sociales, económicas y culturales, tanto externas como internas” (UNESCO, 2008:47). ${ }^{11}$

servicio de un fin concreto y determinado, que reúna las siguientes condiciones: a. Ser resultado y reflejo de movimientos interactivos de personas, así como de intercambios multidimensionales, continuos y recíprocos de bienes, ideas, conocimientos y valores entre pueblos, países, regiones o continentes, a lo largo de considerables períodos de tiempo. b. Haber generado una fecundación múltiple y recíproca, en el espacio y en el tiempo, de las culturas afectadas que se manifiesta tanto en su patrimonio tangible como intangible. c. Haber integrado en un sistema dinámico las relaciones históricas y los bienes culturales asociados a su existencia”.

10 Asimismo, se manifiesta que "esta amplitud es importante desde el punto de vista territorial y del tratamiento integral de los diversos elementos patrimoniales que incluye, pero, a su vez, la diversidad de culturas que entraña se constituye en una alternativa a los procesos de homogeneización cultural" (ICOMOS, 2008, punto 3.3).

11 Por su parte, la International Union for Conservation of Nature (IUCN) incorporó en 1978 la categoría Paisaje Protegido, que fue luego redefinida en 1994 resaltando los valores estéticos, ecológicos y culturales del paisaje. 
Si bien en la definición del Comité de Patrimonio Mundial de 1992 la materialidad prevalece sobre la percepción (Silva Pérez y Fernandez Salinas, 2015), esta comienza a ser un elemento central en las posteriores definiciones. En 2008 se incorporó una clasificación de paisajes culturales, distinguiéndose: a) paisaje claramente definido, concebido y creado intencionalmente por el hombre (e.g. jardines y parques), b) paisaje que ha evolucionado orgánicamente, que se subdivide en dos subcategorías: paisaje relicto (o fósil) es aquel que ha experimentado un proceso evolutivo que se ha detenido en algún momento del pasado, ya sea bruscamente o a lo largo de un periodo y, paisaje vivo es el que conserva una función social activa en la sociedad contemporánea, estrechamente vinculada al modo de vida tradicional. La tercera categoría comprende el paisaje cultural asociativo, dado por las asociaciones religiosas, artísticas o culturales del elemento natural más que en evidencia cultural material, que puede ser insignificante o incluso ausente (UNESCO, 2008:96).

La cuestión de los paisajes culturales, tanto rurales como urbanos, fue luego retomada en diferentes documentos. Caben mencionarse el Memorándum de Viena: Patrimonio Mundial y la Arquitectura Contemporánea. Gestión del Paisaje Histórico Urbano (UNESCO, 2005b) y, en particular, la Recomendación de la UNESCO sobre Paisaje Urbano Histórico de 2011. Allí se entiende por paisaje urbano histórico la zona urbana resultante de una estratificación histórica de valores y atributos culturales y naturales, lo que trasciende la noción de "conjunto" o "centro histórico" para abarcar el contexto urbano general y su entorno geográfico. Este contexto general incluye otros rasgos del sitio, principalmente su topografía, geomorfología, hidrología y características naturales; su medio urbanizado, tanto histórico como contemporáneo; sus infraestructuras, tanto superficiales como subterráneas; sus espacios abiertos y jardines, la configuración de los usos del suelo y su organización espacial; las percepciones y relaciones visuales; y todos los demás elementos de la estructura urbana. También incluye los usos y valores sociales y culturales, los procesos económicos y los aspectos inmateriales del patrimonio en su relación con la diversidad y la identidad. Esta definición sienta las bases de un planteamiento global e integrado para la determinación, evaluación, conservación y gestión de los paisajes urbanos históricos como parte de un plan general de desarrollo sostenible (puntos 8, 9 y 10). Y agrega que "La noción de paisaje urbano histórico tiene en cuenta las tradiciones y percepciones de las comunidades locales a la vez que respeta los valores de la comunidad nacional e internacional" (punto 13).

En el seno de ICOMOS se produjo la Declaración de Florencia (2014), que considera el patrimonio y el paisaje como valores humanos. Allí se indica que el concepto de paisaje, urbano o rural, se está convirtiendo cada vez más en un nuevo paradigma para el desarrollo armonioso, ofreciendo un enfoque que puede integrar los procesos económicos, sociales y ambientales (2.1.a) (ICOMOS, 2014).

El cambio legislativo bajo análisis brinda aire fresco a una ley que se había quedado en el tiempo y, sin duda, genera nuevos desafíos a la Comisión Nacional. Un ejemplo de ello es el Decreto Nacional $N^{\circ} 817 / 2019$, que declaró Paisaje Cultural Nacional al área que comprende 
la cuenca media y baja del río Pinturas, donde se encuentra la Cueva de las Manos, entre otros sitios; asimismo se definió un Área de Amortiguación Visual. Cabe destacar que la Cueva de las Manos era Monumento Histórico Nacional desde $1993^{12}$ y había sido declarada Paisaje Provincial conforme a la Ley $\mathrm{N}^{\circ} 3.394 / 2014$ de la provincia de Santa Cruz.

La nueva categorización se funda en la necesidad de "dar precisión espacial a la declaratoria de monumento histórico nacional, estableciendo su delimitación exacta, con lo que se crearán mejores condiciones para su gestión, conforme lo que establece el artículo $1^{\circ}$ ter de la Ley $\mathrm{N}^{0} 12.665$ en su actual redacción”.

Para la selección de las categorías de Paisaje Cultural Nacional y Área de amortiguación visual se tuvieron en cuenta el marco legal (i.e., lo dispuesto en el artículo $1^{\mathrm{o}}$ ter inciso h) de la Ley $\mathrm{N}^{\circ} 12.665$ y sus modificatorias, en concordancia con la Ley Provincial No 3.394) y las características del lugar, es decir la "extensión y cualidades del territorio implicado y la cantidad y variedad de los bienes arqueológicos que contiene" y las especificidades y necesidades de manejo del mismo (cfr. Decreto $\left.N^{\circ} 817 / 2019\right)$.

\section{b) 2. ACTIVACIÓN PATRIMONIAL}

El segundo ejemplo de introducción de nuevas concepciones del patrimonio cultural en la ley se produce en su decreto reglamentario, el cual faculta a la Comisión a promover la activación patrimonial de los bienes culturales declarados. En esta activación se vislumbra una asociación entre la noción de desarrollo y la de patrimonio cultural que proviene de elaboraciones producidas en el ámbito internacional, en los cuales el concepto de desarrollo tiene a la cultura como una dimensión de facilitación de este.

Esta es la concepción del desarrollo explicitada en la Conferencia de Venecia de 1970 y en la Conferencia Mundial sobre las Políticas Culturales (MONDIACULT). En esta última se aprobó la Declaración de México sobre Políticas Culturales. En la misma se redefinió la noción de cultura, incluyendo los modos de vida, los sistemas de valores, tradiciones y creencias, revalorizando las culturas del Sur (Maraña, 2010). Entre los principios que deben regir las políticas culturales, luego de destacar que la cultura constituye una dimensión fundamental del proceso de desarrollo, expresa que "El crecimiento se ha concebido frecuentemente en términos cuantitativos, sin tomar en cuenta su necesaria dimensión cualitativa, es decir, la satisfacción de las aspiraciones espirituales y culturales del hombre" (Principio 10).

Este, junto a otros principios, delinea una particular concepción del desarrollo. En este sentido, el principio 13, que establece que el objetivo de las personas “...no es la producción, la ganancia o el consumo per se, sino su plena realización individual y colectiva, y la preservación de la naturaleza”, permite referenciar una visión holística del patrimonio. Por su parte, el principio 15 es de notable relevancia, pues introduce el reconocimiento de estilos de desarrollo, al expresar "Se requieren nuevos modelos y es en el ámbito de la cultura y de la educación en donde han de encontrarse." Este reconocimiento es reiterado en el principio 41 referente a Administración, Planificación y Financiamiento de las Actividades Culturales, el cual da cuenta 
que para realizar estas actividades “...se han de tomar en consideración las necesidades y problemas de cada sociedad...”. De este modo la Declaración de México sobre Políticas Culturales define un desarrollo que excede las consideraciones exclusivamente económicas y que se encuentra integrado indisolublemente por una dimensión cultural.

\section{b) 3. Área de amortiguación}

Finalmente, el tercer elemento que se incorpora para modificar la noción de patrimonio cultural es la noción de área de amortiguación. En este sentido, el artículo 1 ter g) establece como una facultad de la Comisión "Establecer 'áreas de amortiguación' en el entorno de los monumentos, coordinando con la autoridad local las restricciones urbanísticas que correspondan”.

La consideración del entorno, originada en documentos internacionales de soft law, provenientes de organizaciones no gubernamentales (como ICOMOS) y organizaciones internacionales (como OEA), se cuela así en la regulación nacional, involucrando asimismo competencias municipales (Levrand, 2018). El entorno o área de amortiguación representa una zona que, por sí, no contiene un valor excepcional, pero que puede influir en la conservación de un bien cultural.

La noción aparece descripta en las Directrices para la Aplicación de la Convención del Patrimonio Mundial, Cultural y Natural de 2008, como "un área alrededor del bien cuyo uso y desarrollo están restringidos jurídica y/o consuetudinariamente a fin de reforzar su protección" (Directrices, parágrafo 104). La inclusión de la protección de un área adyacente al bien es una novedad en el ámbito de la tutela del patrimonio cultural. Históricamente desarrollada en la protección de monumentos y sitios históricos o de valor científico, las herramientas jurídicas para la protección se concretaban en la tutela del bien en sí. Particularmente importante fue la utilización de la declaración de interés público de los bienes y su expropiación por parte del Estado en la protección del patrimonio cultural. Esta herramienta jurídica implica, para un Estado con erogaciones siempre limitadas, la estricta delimitación del bien y de su valor pecuniario. Por otra parte, herramientas provenientes del derecho urbanístico, como la zonificación de áreas de patrimonio cultural, parecen ser el germen de este tipo de normas.

Un caso emblemático en este aspecto tuvo lugar a partir de la intención de construir un centro comercial en las inmediaciones de la Estancia Jesuítica de Caroya (inscripta en la Lista del Patrimonio Mundial en 1999). Este proyecto fue sometido al dictamen de la Comisión y del organismo de enlace con UNESCO (CONAPLU), quienes exigieron la preparación de una normativa urbana del área. De este modo, la Municipalidad de Colonia Caroya proyectó en 2012 la Ordenanza por la cual se establecía el Manual de Procedimientos para las Actuaciones en el Área Especial de Protección Estancia Jesuítica de Caroya. A fin de satisfacer la normativa administrativa de los diversos organismos mencionados, previo a su aprobación, el proyecto fue enviado en consulta a los mismos. Estos organismos realizaron observaciones en el proyecto, destinadas a modificar algunos aspectos de este. 
Dos cuestiones llaman profundamente la atención en las observaciones de ambos organismos. Por una parte, la adecuación de la normativa municipal a las Directrices Prácticas de la UNESCO. En este sentido, la intersección de normas de diversos niveles se observa claramente.

La autonomía municipal ha sido reconocida por la Carta Magna desde su sanción, y desde aquel momento los problemas del federalismo han sido núcleo de discusiones en la doctrina jurídica. Hasta hace poco tiempo, la intervención de organismos nacionales en la redacción de una norma urbanística, de clásica competencia municipal, hubiese sido impensada. El ordenamiento, la gestión y el control del uso del suelo han sido y son temáticas fundamentales del derecho urbanístico de clásica competencia material municipal (Taller y Antik, 2011). No obstante, la incidencia de la normativa internacional en el caso concreto resulta en una interpenetración e interrelación de procesos globales y procesos nacionales (Dezalay y Trubek, 1997).

El segundo punto que merece destacarse es el ámbito de actuación de la Comisión. En el caso que comentamos, la Estancia Caroya ha sido declarada monumento histórico nacional y se encuentra bajo la superintendencia de la Comisión. No obstante, el área de amortiguación que fue presentada a la UNESCO excede el límite del bien que oportunamente fue declarado a nivel nacional. Ello evidentemente debe ser así, atento a las finalidades del área de amortiguación que ya se mencionaron.

Pese a ello, la Comisión manifestó preocupación por un entorno que la ley nacional no protegía hasta 2015. La posibilidad de actuación sobre este objeto puede rastrearse hasta la recepción de la Disposición Interna $\mathrm{N}^{\circ} 5 / 91$ de la Comisión por la cual se adopta para las decisiones del cuerpo colegiado la "valoración e inclusión del entorno físico-ambiental”. El fundamento de esta modificación de criterios se realiza conforme la propia disposición correspondiéndose con la opinión de los expertos y las recomendaciones formuladas en los congresos de especialistas.

En el caso que tratamos, evidentemente, la traducción de criterios expertos en normas jurídicas genera una distorsión del sistema al no encuadrarse en el paradigma existente. La protección del entorno no estaba regulada en el ordenamiento jurídico nacional argentino al momento de la redacción del dictamen por parte de la Comisión, por lo cual su asunción por parte de un organismo gubernamental tensiona fuertemente las competencias de este y de otros niveles estatales (en este caso la municipalidad).

En otro orden, la resistencia entre la demarcación de un área de amortiguación y el derecho de dominio previsto en el Código Civil y Comercial se muestra insalvable en un paradigma dicotómico de la propiedad (Sozzo, 2009). El mismo puede identificarse a partir de una separación tajante entre las esferas pública y privada, que fundamenta un discurso individualista, fuertemente anclado en el inconsciente colectivo. Este discurso se mantiene a pesar de la inserción de límites al ejercicio del derecho de propiedad en virtud de la proyección de derechos de incidencia colectiva (art. 240 del CCyC). 


\section{CONCLUSIONES}

El interés del Estado Argentino por crear un organismo de nivel nacional cuya función principal fuera tutelar los bienes monumentales que formaban parte de la identidad se consolidó en 1940 con la creación de la Comisión Nacional de Museos, de Monumentos y de Lugares Históricos. Los cambios en la concepción del patrimonio cultural a nivel internacional y en los ámbitos académicos, como también diversas dificultades que se observaron en el funcionamiento de esta Comisión, motivaron un conjunto de iniciativas que tenían por finalidad la modificación de la ley de creación.

En 2015 una de estas iniciativas se convirtió en la Ley $\mathrm{N}^{\circ}$ 27.103, modificatoria de la norma original, la Ley $\mathrm{N}^{\circ}$ 12.665. A lo largo de este trabajo nos hemos centrado en analizar el contexto jurídico de producción de la norma y las influencias que las normas de soft law han producido en el ordenamiento vigente a partir de dos modalidades de introducción: a) en las prácticas administrativas de la Comisión y b) en la adopción de estándares internacionales para reconceptualizar el patrimonio cultural.

En la trama histórica cercana, la modificación de la Constitución Nacional promovió el derecho al patrimonio cultural como un derecho fundamental. En este sentido, su protección (y consecuentemente la actuación de la Comisión) debe considerarse entre los intereses primordiales del Estado. A la par de ello, la consideración jurídica de los tratados con jerarquía similar a las leyes nacionales permite interpretar un conjunto de convenciones ratificadas por Argentina como integrantes del derecho a la cultura. No obstante, esta consideración es acompañada por normas de soft law, las que, al haber surgido de los propios organismos internacionales que elaboran los tratados, complementan y regulan a los mismos.

La reforma del Código Civil y Comercial, en 2014, incorporó nuevas categorías como los "valores culturales" y "el paisaje" asociados a una limitación al ejercicio de los derechos individuales de propiedad. De este modo, la concepción decimonónica de propiedad vigente hasta el momento comienza a templarse ante nuevas categorías.

La propia Comisión actualizó, durante la década de 1990, los criterios del Registro Nacional de Bienes Históricos e Histórico-Artísticos a fin de adecuarlos a las nuevas reflexiones producidas en el ámbito académico internacional.

Es decir que en el momento en que se propone la modificación de la Ley $\mathrm{N}^{\circ} 12.665$, el ordenamiento jurídico nacional había reconocido el derecho a la cultura, estableciendo limitaciones al dominio en pos de la preservación de los bienes patrimoniales, brindando las condiciones para una armonización de la antigua ley conforme a los nuevos paradigmas de conceptualización y gestión del patrimonio cultural.

No obstante, un somero análisis de los proyectos de reforma legislativa presentados permite dar cuenta de la reiteración de tópicos en los mismos: la inclusión de nuevas categorías de bienes; la consideración de las áreas de amortiguación o del entorno de los monumentos y el establecimiento de un presupuesto propio para la Comisión. El proyecto que se convirtió en Ley $\mathrm{N}^{\circ} 27.103$ no dista de estos patrones. 
La observación de los estándares incluidos en la reforma permite comprobar la influencia directa de normas de soft law producidas en el ámbito internacional sobre la regulación nacional. Su incorporación es explícita además en un conjunto de cláusulas presentes en la Ley $\mathrm{N}^{\circ} 27.103$ y en su decreto reglamentario que habilitan a la Comisión a aplicar normas de soft law a pesar de que las mismas no forman parte del ordenamiento jurídico argentino. Las posibilidades de emitir recomendaciones acerca del patrimonio cultural abren una nueva vía de actuación para la Comisión, que, siguiendo el modelo de derecho flexible, puede producir lineamientos de gestión o declaración de sitios sin eficacia jurídica. Al mismo tiempo, se habilita a introducir, en estas recomendaciones, los criterios que los expertos sostienen en el orden internacional, respaldándose de este modo una actuación uniforme. En esta actividad, el lugar de los expertos es fundamental, posibilitando adecuar la norma nacional a los criterios adoptados internacionalmente o generando adaptaciones para problemas concretos.

Por otra parte, se ha analizado la manera en que un conjunto de nociones que moldean el concepto de patrimonio cultural en el ámbito internacional ha sido receptado en la reforma. En este sentido, la introducción de nuevas categorías de protección (como los paisajes y los itinerarios culturales), la consideración de la dimensión cultural del desarrollo sustentable o la implementación de una delimitación de áreas de amortiguación de los monumentos configuran implantaciones directas de concepciones establecidas en normas de soft law. Algunas de estas nociones ya se encontraban presentes en la actuación previa de la Comisión (como algunas categorías novedosas incluidas en la década de 1990 en el Registro Nacional). Así, no es posible interpretar estas modificaciones aisladas del contexto en el cual se producen.

Las nuevas introducciones de la norma reformada aún no han tenido, a pesar del tiempo transcurrido, un impacto relevante en la actuación de la Comisión. Probablemente el organismo requiera cierto tiempo para adecuar su accionar a las nuevas concepciones vigentes en la ley. Seguramente la ausencia de una consulta y trabajo conjunto en el proceso de reforma impide una adopción expedita de las mismas, sumado al recambio de funcionarios del área generado a partir del cambio de gobierno. A pesar de ello, considerar la incidencia del soft law en las modificaciones a la ley permite vislumbrar la magnitud de los cambios realizados en pos de adecuar la normativa nacional a los estándares internacionales, al tiempo que deja sin saldar muchos de los reclamos que la propia Comisión tiene respecto a las posibilidades de su gestión. 


\section{AGRADECIMIENTOS}

A todos aquellos que generosamente prestaron su tiempo para ser entrevistados. Este trabajo fue realizado en el marco de las investigaciones desarrolladas por PATRIMONIA (Programa Interdisciplinario de Estudios del Patrimonio), INCUAPA (U.E. CONICET - UNICEN), financiado a traves del proyecto PICT 0551 / 16, dirigidos por María Luz Endere y financiado por la ANPCyT.

\section{BIBLIOGRAFÍA}

ARGENTINA. Constitución Nacional (1994). Disponible en: <http://servicios.infoleg.gob.ar/ infolegInternet/anexos/0-4999/804/norma.htm>. Accedido el 30 de julio de 2019.

. Código Civil y Comercial. Disponible en: <http: / / servicios.infoleg.gob.ar/infolegInternet/ anexos/235000-239999/235975/norma.htm>. Accedido el 30 de julio de 2019.

. Ley $\mathrm{N}^{\circ}$ 9.080, del 26 de febrero de 1913. Disponible en: <http:/ / www.loa.org.ar/legNorma Detalle.aspx?id=2988> . Accedido el 30 de julio de 2019.

Ley $\mathrm{N}^{\circ}$ 12.665, del 15 de octubre de 1940. Disponible en: <http://servicios.infoleg.gob.ar/ infolegInternet/verNorma.do?id=23121>. Accedido el 30 de julio de 2019.

Ley $N^{\circ}$ 19.943, del 13 de noviembre de 1972. Aprueba la Convención sobre las medidas que deben adoptarse para prohibir e impedir la importación, la exportación y transferencia de propiedad ilícitas de bienes culturales. Disponible en: <http: / servicios.infoleg.gob.ar/infolegInternet/anexos / 8500089999/85129/norma.htm>. Accedido el 30 de julio de 2019.

. Ley N $\mathrm{N}^{\mathrm{2}} 21.836$, del 6 de julio de 1978. Aprueba la Convención sobre la Protección del Patrimonio

Mundial, Cultural y Natural. Disponible en: <http: / / servicios.infoleg.gob.ar/infolegInternet/anexos / 215000-219999/215908/norma.htm>. Accedido el 30 de julio de 2019.

. Ley $\mathrm{N}^{\circ}$ 23.313, del 6 de mayo de 1986. Aprueba el Pacto Internacional de Derechos Económicos, Sociales y Culturales. Disponible en: <http://servicios.infoleg.gob.ar/infolegInternet/anexos/2000024999/23782/norma.htm>. Accedido el 3 de agosto de 2019. 
Ley N $\mathrm{N}^{\mathrm{2}} 23.618$, del 20 de octubre de 1988. Aprueba la Convención para la Protección de los Bienes Culturales en caso de Conflicto Armado. Disponible en: <http: / servicios.infoleg.gob.ar / infolegInternet/anexos/0-4999/20/norma.htm>. Accedido el 30 de julio de 2019.

Ley $\mathrm{N}^{\circ}$ 24.225, del 23 de junio de 1993. Monumentos y Lugares Históricos, Cueva de las Manos. Disponible en <https://www.argentina.gob.ar/normativa/nacional/ley-24225-621>. Accedido el 10 de diciembre de 2019.

Ley $N^{\circ}$ 25.197, del 15 de diciembre de 1999. Regimen del Registro del Patrimonio Cultural. Disponible en: <http://servicios.infoleg.gob.ar/infolegInternet/verNorma.do?id=61480>. Accedido el 30 de julio de 2019.

. Ley $\mathrm{N}^{\mathrm{o}}$ 25.257, del 15 de junio de 2000. Aprueba la Convención del UNIDROIT sobre Objetos Culturales Robados o Exportados Ilegalmente. Disponible en: <http: / / servicios.infoleg.gob.ar / infolegInternet/anexos/60000-64999/63763/norma.htm>. Accedido el 30 de julio de 2019.

Ley N $N^{\circ}$ 25.568, del 10 de abril de 2002. Aprueba la Convención sobre Defensa del Patrimonio Arqueológico, Histórico y Artístico de las Naciones Americanas - Convención de San Salvador. Disponible en: <http://servicios.infoleg.gob.ar/infolegInternet/anexos/70000-74999/74072/norma.htm>. Accedido el 30 de julio de 2019.

Ley N $\mathrm{N}^{\mathrm{2}} 26.118$, del 25 de julio de 2006. Aprueba la Convención para la Salvaguardia del Patrimonio Cultural Inmaterial. Disponible en: <http: / / servicios.infoleg.gob.ar/infolegInternet/anexos/ 115000-119999/118206/norma.htm>. Accedido el 30 de julio de 2019.

Ley $\mathrm{N}^{\mathrm{0}}$ 26.305, del 26 de diciembre de 2007. Aprueba la Convención sobre la Protección y Promoción de la Diversidad de las Expresiones Culturales. Disponible en: < http: / / servicios.infoleg. gob.ar/infolegInternet/anexos/135000-139999/135906/norma.htm>. Accedido el 30 de julio de 2019.

Ley $\mathrm{N}^{\circ}$ 26.556, del 15 de diciembre de 2009. Aprueba la Convención sobre la Protección del Patrimonio Cultural Subacuático. Disponible en: <http://servicios.infoleg.gob.ar/infolegInternet/ anexos/160000-164999/161543/norma.htm>. Accedido el 30 de julio de 2019.

Ley $N^{o} 27.103$ del 23 de enero de 2015. Monumentos y Lugares Históricos. Disponible en: <http://servicios.infoleg.gob.ar/infolegInternet/anexos/240000-244999/241196/norma.htm>. Accedido el 30 de julio de 2019.

. Decreto Reglamentario N 84.005, del 7 de febrero de 1941. Disponible en: <http: / /www.saij. gob.ar/84005-nacional-decreto-reglamentario-ley-12665-creacion-comision-nacional-museos-monumentos- 
lugares-historicos-dn19410084005-1941-02-07/123456789-0abc-500-4800-1491soterced >. Accedido el 30 de julio de 2019.

. Decreto Reglamentario No 2.525, del 2 de diciembre de 2015. Disponible en: <http:/ /servicios. infoleg.gob.ar/infolegInternet/verNorma.do\%3Bjsessionid=DF24DE762BF7417E992D8AEAD47973D0 ?id=255982> . Accedido el 30 de julio de 2019.

. Decreto $N^{o} 819$, del 5 de diciembre de 2019. Disponible en: <https://www.boletinoficial. gob.ar/\#!DetalleNorma/223062/20191206 > . Accedido el 10 de diciembre de 2019.

ARGENTINA, Corte Suprema de Justicia de la Nación. Fallos de la CSJN. 143:432. Buenos Aires, Imprenta Oficial, 1923.

Zorrilla Susana y otro c/ E.N. - P.E.N. s/ expropiación-servidumbre administrativa. Fallos de la CSJN. 336:1390. Buenos Aires, Imprenta Oficial, 2013.

CASSAGNE, J. C. e IBARZÁBAL, M. La protección del patrimonio cultural en la ley 27.103. Revista de Derecho Ambiental, 105, 677-686, 2016.

COLOMBATO, L. El derecho humano a los patrimonios culturales. Avances, frenos y retos de su consolidación desde La Pampa. La Pampa: EdUNLPam, 2016.

COMISIÓN NACIONAL DE MUSEOS, MONUMENTOSY LUGARES HISTÓRICOS. Disposición Interna $\mathrm{N}^{\circ}$ 5/1991. Archivo de la CNMMyLH.

Disposición Interna No 6/1991. Archivo de la CNMMyLH.

CORDERO QUINZACARA, E. De la propiedad a las propiedades. La evolución de la concepción liberal de la propiedad. Revista de Derecho de la Pontificia Universidad Católica de Valparaíso, No XXXI, Valparaíso, 2008, 493-525.

DEZALAY, Y. y TRUBEK, D. La reestructuración global y el derecho. La internacionalización de los campos jurídicos y la creación de espacios transnacionales. Revista Pensamiento Jurídico, $\mathrm{N}^{\mathrm{o}} 1$, $1997,5-41$.

ENDERE, M. L. Arqueología y legislación en Argentina. Cómo preservar el patrimonio arqueológico. Tandil: Departamento de Publicaciones de la UNCPBA, 2000, v. I. Serie Monográfica INCUAPA. 
ENDERE, M. L., CHAPARRO M. G. y WILliAMS V. Tolombón: Arqueología y Comunidad. En: WILliams, V. y CREMONTE, B. Al Borde del Imperio. Paisajes Sociales en Áreas Periféricas del Qollasuyu. Buenos Aires: Publicaciones de la SAA, 2013. pp. 209-220.

ENDERE, M. L. y COLOMBATO, L. The new Unified Civil and Commercial Code and Cultural Heritage Protection in Argentina. International Journal of Cultural Property, 24, 2017, 79-99.

ENDERE, M. L. y ROLANDI, D. Legislación y gestión del patrimonio arqueológico. Breve reseña de lo acontecido en los últimos 70 años. Relaciones de la Sociedad Argentina de Antropología, 32 , 2007, 33-54.

EAÍN, J. Competencias Ambientales. Buenos Aires: Lexis Nexis, 2008.

GALBRAITH, J. y ZARING, D. Soft law as foreign relations law. Cornell Law Review, 99, 2014, 735-794. Disponible en: <http://scholarship.law.cornell.edu/clr/vol99/iss4/2>. Accedido el 3 de mayo de 2014.

HAIDAR, V. et al. ¿20 años no es nada? Un estudio de los debates constituyentes de 1994 sobre ambiente y patrimonio cultural. Revista de la Facultad de Ciencias Jurídicas y Sociales. Nueva Época, Universidad Nacional del Litoral, 9, 12-2014, 65-81.

ICOMOS. Carta de itinerarios culturales. 2008. Quebec, Canadá. Disponible en: <https:// www.icomos.org/images/DOCUMENTS/Charters/culturalroutes_sp.pdf $>$. Accedido el 3 de junio de 2019.

JAMESON, J. International Conventions and Charters and Archaeology Presentation. En SMITH C. (ed.). Encyclopedia of Global Archaeology. Section: Legislation. Nueva York: Springer, 2014, 3948-3954.

LEVRAND, N. Política legislativa vs. Diversidad cultural: el desafío de proteger nuestro patrimonio cultural, en SOZZO, G. (Ed./Comp.). La protección del Patrimonio Cultural. Estudios socio jurídicos para su construcción. Santa Fe: UNL, 2009, 59-98.

. Normas de presupuestos mínimos de protección del patrimonio cultural en argentina:¿ Posibles y vigentes?. E-rph-Revista electrónica de Patrimonio Histórico, 16, 2015, 34-52.

Análisis de la multiplicidad de competencias y regulaciones en un sitio del patrimonio mundial Argentino. Inciso, 18, 2, 2016, 9-19. 
La regulación del Patrimonio Mundial Cultural en Argentina. Dominio, competencias y significaciones. 2017. Tesis para acceder al grado de Doctora en Derecho. Facultad de Ciencias Jurídicas y Sociales, Universidad Nacional del Litoral. Santa Fe, 2017a, inédita.

. Disciplinas y Universidad en la protección del patrimonio histórico- artístico en Argentina: 19371946. Jornadas Nacionales de Historia de la Universidad Argentina, 2017b, Mendoza.

La tutela jurídica del patrimonio cultural bajo la influencia del soft law. Estudio del caso Misiones Jesuíticas Guaraníes en Argentina. Cuadernos del Claeh, 37, 108, 2018, 121-142.

LOREnZETTI, R. Teoría del Derecho Ambiental. Buenos Aires: La Ley, 2008.

El paisaje: un desafío en la teoría jurídica del derecho ambiental. Aavv Edición Homenaje al Dr. Jorge Mosset Iturraspe. Santa Fe: EdUNL, 2005, 315-319.

MARAÑA, M. Cultura y desarrollo. Evolución y perspectivas. UNESCO Etxea, 2010. Disponible en: $<$ http://www.unescoetxea.org/dokumentuak/Cultura_desarrollo.pdf $>$. Accedido el 15 de agosto de 2016.

MAZUELOS BELLIDO, A. Soft Law ¿mucho ruido y pocas nueces?. Revista electrónica de estudios internacionales (REEI), 8, 2004. Disponible en: <www.reei.org/index.php/revista/num8/archivos / MazuelosBellido_reei8_.pdf $>$. Accedido el 12 de mayo de 2015.

MEREMINSKAYA, E. y MASCAREÑO, A. Desnacionalización del derecho y la formación de regímenes globales de gobierno. En MARTINIC, M. (Ed.). Sesquicentenario del Código Civil de Andrés Bello: Pasado, presente y futuro. Santiago: Lexis-Nexis, 2005, 1391-1427.

MOLINA, M. Las limitaciones administrativas en la legislación argentina sobre patrimonio cultural. La Ley Gran Cuyo, 1, 2017, 2509-2519.

MOREU CARBONELL, E. Desmitificación, privatización y globalización de los bienes públicos: del dominio público a las "obligaciones de dominio público". Revista de Administración Pública, 161, 2003, 435-477.

ORGANIZACIÓN DE ESTADOS AMERICANOS. Recomendación relativa a la protección de la belleza y del carácter de los lugares y paisajes, del 11 de diciembre de 1962. Disponible en: <http://portal. unesco.org/es/ev.php-URL_ID=13067\&URL_DO=DO_TOPIC\&URL_SECTION=201.html>. Accedido el 30 de julio de 2019. 
PROVINCIA DE SANTA CRUZ. Ley No 3.394, del 25 de septiembre de 2014. Paisaje natural y cultural "Cuenca Media e Inferior del Río Pinturas". Disponible en <http://www.saij.gob.ar/3394-local-santacruz-paisaje-natutal-cultural-cuenca-media-inferior-rio-pinturas-lpz0003394-2014-09-25/123456789-0abc -defg-493-3000zvorpyel?\&o=21\&f=Total\%7CFecha/2014\%5B20\%2C1\%5D\%7CEstado\%20de\%20Vigencia/ Vigente $\% 2 \mathrm{C} \% 20 \mathrm{de} \% 20$ alcance $\% 20$ general\%7CTema $\% 5 \mathrm{~B} 5 \% 2 \mathrm{C} 1 \% 5 \mathrm{D} \% 7 \mathrm{COrganismo} \% 5 \mathrm{~B} 5 \% 2 \mathrm{C} 1 \% 5 \mathrm{D} \%$ 7CAutor\%5B5\%2C1\%5D\%7CJurisdicci\%F3n/Local/Santa\%20Cruz\%7CTribunal\%5B5\%2C1\%5D\%7C Publicaci\%F3n\%5B5\%2C1\%5D\%7CColecci\%F3n\%20tem\%E1tica\%5B5\%2C1\%5D\%7CTipo\%20de\%20 Documento/Legislaci\%F3n/Ley\&t=63>. Accedido el 10 de diciembre de 2019.

RATNER, S. International Law: the trials of global norms. Foreign Policy, 110, 1998. Disponible en: <https://www.jstor.org/stable/1149277?seq=1\#page_scan_tab_contents>. Accedido el 13 de mayo de 2014.

REYNA, J. Fundamentos del Principio constitucional de actuación conjunta para la tutela especial de derechos fundamentales. En GARCÍA PÉREZ, M. y RODRÍGUEZ-ARANA MUÑOZ, J. (dir.). Cuestiones actuales del Derecho Público. Estudios en homenaje a la Dra. Irmgard Lepenies. Madrid: Derecho Público Global, 2014: 657-696.

RODOTÁ, S. El terrible derecho. Estudios sobre propiedad privada. Trad. Luis Díez-Picaso. Madrid: Civitas, 1986.

RODRÍGUEZ, J. C. Nueva ley de monumentos y lugares históricos. La Ley. Buenos Aires, 21 de abril de 2015, Suplemento de Actualidad.

SILVA PÉREZ, R. y FERNÁNDEZ SALINAS, V. Los paisajes culturales de Unesco desde la perspectiva de América Latina y el Caribe. Conceptualizaciones, situaciones y potencialidades. Revista INVI, 30(85), 2015, 181-212.

SOZZO, G. El Arca cultural: entre lo público y lo privado, un proyecto democratizador de la Propiedad Privada (el caso de la tutela del Patrimonio Cultural en la Provincia de Santa Fe, República Argentina). En SOZZO G. (Dir. / Coord.) La protección del Patrimonio Cultural. Estudios sociojurídicos para su construcción. Santa Fe: UNL, 2009, 13-58.

Derecho privado ambiental. Santa Fe: Rubinzal Culzoni. 2019.

TAlleR, A. y ANTIK, A. Curso de Derecho Urbanístico. Santa Fe: Rubinzal-Culzoni, 2011.

UNESCO. Convención sobre la protección del patrimonio mundial, cultural y natural. World Heritage Centre. 1972. Disponible en: <http:// whc.unesco.org/archive/convention-es.pdf>. Accedido el 15 de mayo de 2019. 
. Conferencia Intergubernamental sobre los Aspectos Institucionales, Administrativos y Financieros de las Políticas Culturales. 1970. Disponible en: <https://culturalrights.net/es/documentos.php?c=18\&p= 197>. Accedido el 3 de agosto de 2019.

. Recomendación relativa a la protección de la belleza y el carácter de los lugares. 1962. Disponible en: <http://portal.unesco.org/es/ev.php-URL_ID=13067\&URL_DO=DO_TOPIC\&URL_SECTION= 201.html>. Accedido el 15 de mayo de 2019.

Conferencia mundial sobre las políticas culturales: informe final. Disponible en: <https: / / unesdoc.unesco.org/ark:/48223/pf0000052505_spa>. Accedido el 3 de agosto de 2019.

Recomendación sobre la Salvaguardia de la Cultura Tradicional y Popular. 1989. Disponible en: <http: / portal.unesco.org/es/ev.php-URL_ID=13141\&URL_DO=DO_TOPIC\&URL_SECTION $=201 . \mathrm{html}>$. Accedido el 30 de julio de 2019 .

Memorándum de Viena sobre el Patrimonio Mundial y la Arquitectura Contemporánea. Gestión del Paisaje Histórico Urbano. 2005. Disponible en: <http:/ /www.journals.unam.mx/index. $\mathrm{php} / \mathrm{mecedupaz} /$ article/view/57157>. Accedido el 3 de agosto de 2019.

Recomendación sobre el paisaje urbano histórico, con inclusión de un glosario de definiciones. 2011. Disponible en: <http://portal.unesco.org/es/ev.php-URL_ID=48857\&URL_DO= DO_TOPIC\&URL_SECTION=201.html>. Accedido el 15 de mayo de 2019.

. Directrices Prácticas para la aplicación de la Convención del Patrimonio Mundial. 2008. WHC. 08/01, París: UNESCO.

Annex 3. Guidelines on the inscription of specific types of properties on the World Heritage List. Operational Guidelines for the Implementation of the World Heritage Convention. 2017. WHC.17/01. París: UNESCO.

VERA, A. Bienes colectivos en el nuevo código civil: el ejercicio de un derecho entre lo público y lo privado.

Revista de Derecho Ambiental, Buenos Aires, Lexis-Nexis, 46, 2016, 85-93. 


\section{COMO CITAR ESTE ARTIGO:}

LEVRAND, Norma Elizabeth; ENDERE, María Luz. Nuevas categorías patrimoniales. La incidencia del soft law en la reciente reforma a la ley de patrimonio histórico y artístico de Argentina. Revista Direito GV, v. 16, n. 2 , maio/ago. 2020, e1960. doi: http://dx. doi.org/10.1590/2317-6172201960.

\author{
Norma Elizabeth Levrand \\ Doctora en Derecho, Instituto de Estudios Sociales \\ (CONiCet - Uner), Paraná, Entre Ríos, Argentina. \\ normalevrandagmail.com \\ María Luz Endere \\ PhD, Master in Museum and Heritage Studies. \\ PATRIMONIA - INCUAPA (UE CONICET-UNICEN), \\ Facultad de Ciencias Sociales, Universidad Nacional del \\ Centro de la Provincia de Buenos Aires. \\ menderelasoc.unicen.edu.ar
}

